\title{
Sujeitos, Políticas e Educação Ambiental na Gestão de Resíduos Sólidos
}

\author{
Leandro Rogério Pinheiro' \\ Márcio de Freitas do Amaral' \\ Cassiano Pamplona Lisboa" \\ Tiago de Mello Cargnin "I"
} 'Universidade Federal do Rio Grande do Sul (UFRGS), Porto Alegre/RS - Brasil "InstitutoFederal deEducação, CiênciaeTecnologiadoRS(IFRS), PortoAlegre/RS-Brasil

"'Centro Universitário La Salle (Unilasalle), Canoas/RS - Brasil

RESUMO - Sujeitos, Políticas e Educação Ambiental na Gestão de Resíduos Sólidos. As análises que apresentamos aqui se configuram na articulação com os debates sobre a sustentabilidade do modelo de produção e consumo que temos gerado, problematizando políticas e práticas educativas gestadas na constituição e funcionamento das atividades de coleta seletiva e reciclagem. Procuramos, neste ínterim, abordar relações, tomadas de posição e contradições que constituem os aparatos públicos de reciclagem, considerando as narrativas dos principais sujeitos atuantes: catadores, intermediários da comercialização e gestores públicos. Assim, analisamos as práticas em educação ambiental promovidas, esboçando algumas críticas ao que nos parece sua atual ênfase na normatização de condutas.

Palavras-chave: Políticas Públicas. Educação Ambiental. Gestão de Resíduos Sólidos. Tomadas de Posição.

\begin{abstract}
Subjects, Policies and Environmental Education on Solid Waste Management. The analyses presented in this research represent the result of discussions about sustainability of the production and consume model we have created, highlighting the issues regarding educational practices and policies engendered by the constitution and procedures of the activities of selective collection and recycling. In this study, then, the position-taking and the contradictions that comprise the public means of recycling were sought to be analyzed by considering the reports of the main subjects involved in this process, namely, trash pickers, commercial intermediaries and public administrators. Therefore, the praxis in environmental education was approached by criticizing what seems to be the current emphasis regarding behavioural normatizations.

Keywords: Public Policies. Environmental Education. Solid Waste Management. Position-taking.
\end{abstract}

Educação \& Realidade, Porto Alegre, v. 39, n. 2, p. 535-556, abr./jun. 2014.

Disponível em: <http://www.ufrgs.br/edu_realidade> 
Sujeitos, Políticas e Educação Ambiental na Gestão de Resíduos Sólidos

Este trabalho se insere nas discussões acerca das políticas e práticas em educação ambiental, trabalhando mais especificamente a forma como esta se materializa junto aos aparatos públicos constituídos para a reciclagem de resíduos sólidos. Neste sentido, as análises que apresentamos se configuram na articulação com os debates sobre a sustentabilidade do modelo de produção e consumo que temos gerado, problematizando proposições educativas gestadas na constituição e funcionamento do que chamaremos, aqui, de uma cadeia produtiva para a reciclagem ${ }^{1}$.

Os aparatos públicos e as práticas de reciclagem são dados a ver em conotações positivadas, imbuídos de apelos à participação dos citadinos e, parece-nos, dispostos a influir na formação das pessoas em direção a posturas vinculadas a certa atenção/cuidado com o meio ambiente (ainda que possamos discutir a polissemia nos usos deste termo).

Interessa-nos, então, contribuir criticamente a tais práticas, discutindo relações, tomadas de posição e contradições que constituem os aparatos públicos de reciclagem, considerando as narrativas dos principais sujeitos atuantes: catadores, intermediários da comercialização e gestores públicos, destacando especialmente os depoimentos produzidos por estes últimos no que concerne à gestão e à educação ambiental.

Na apresentação de nossos argumentos, iniciaremos pelas opções teórico-metodológicas que orientam nossa problematização, passando a algumas das condições históricas que trouxeram o tema ambiental (e as tensões que este carrega) para o cerne da gestão pública de resíduos, aproximando-nos do que Lopes (2006) refere como processo de ambientalização. Passaremos, depois, à configuração do sistema de coleta seletiva dos municípios visitados, assinalando posições ocupadas pelos principais sujeitos que a conformam ${ }^{2}$. Por fim, abordaremos as práticas em educação ambiental impetradas, esboçando algumas críticas ao que nos parece sua atual ênfase na normatização de condutas.

\section{Sobre os Referentes do Itinerário Investigativo}

Conduzida junto à população de catadores/recicladores ${ }^{3}$ organizados em associações ou grupos de trabalho existentes nos estados do Paraná, do Rio Grande do Sul e de Santa Catarina, a pesquisa se refere a unidades de triagem localizadas em 11 cidades $^{4}$, distribuídas por distintas sub-regiões estaduais, com diferentes atividades produtivas centrais e níveis de crescimento socioeconômico. Convém mencionar que na primeira etapa da investigação, realizada no estado do Rio Grande do Sul, a seleção dos municípios foi operada segundo critérios de localização geográfica (em relação à região metropolitana de Porto Alegre) e observando quatro faixas populacionais: até 50 mil habitantes; de 50 mil a 200 mil habitantes; de 200 mil a 500 mil habitantes, mais de 500 mil habitantes. O objetivo principal desses recortes foi ponderar possíveis influências de características locais (diferentes contextos sociocultu- 
rais) sobre o perfil do catador de materiais recicláveis, de modo a orientar a seleção dos municípios nas etapas subsequentes da investigação. A região metropolitana foi estabelecida como referência para contraste por ser a área de maior densidade populacional do estado, agrupando cidades em situação de conurbação e onde a migração pendular é mais acentuada. Ademais, adotando a hipótese de uma relação positiva (diretamente proporcional) entre contingente populacional e volume na produção de resíduos, conforme sinaliza a Pesquisa Nacional de Saneamento Básico (PSNB/IBGE, 2002), seria também o espaço com mais potencialidade para concentração de associações de catadores.

Os resultados obtidos na primeira etapa da pesquisa orientaram a seleção dos municípios nos estados do Paraná e de Santa Catarina. Nestes, levando em consideração a relação entre esforço amostral (incluindo-se aí os investimentos dispensados com a realização da pesquisa) e a retenção de informações, tornou-se mais produtivo focalizar os esforços de pesquisa nas regiões com maior densidade populacional, uma vez que concentram os maiores contingentes de catadores e de unidades de triagem, assim como as mais significativas variações nos indicadores utilizados para o delineamento dos perfis socioeducacionais (complexidade da amostra). Destarte, apenas municípios localizados em regiões metropolitanas foram considerados nesses estados.

Quanto aos coletivos consultados, foram selecionados segundo critérios de estruturação física e operacional das instalações, filiações políticas, vinculações comunitárias e distribuição geográfica em cada um dos municípios. Nossos diálogos com os distintos sujeitos atuantes no campo incluíram aplicação de questionários para levantamento sociodemográfico, a realização de entrevistas sobre as trajetórias de trabalho e vida dos catadores e levantamento sobre as condições de gestão e trabalho nas associações consideradas, além dos contatos e entrevistas com representantes do poder público e de organizações não-governamentais (ONGs) que assessoram as associações.

Neste artigo, o foco na gestão pública dos aparatos de reciclagem decorre da compreensão do campo ambiental como um campo social, nos termos colocados por Bourdieu (2007; 2011), logo “[...] necessariamente engajado na disputa pelo poder simbólico de nomear e atribuir sentido ao que seria a conduta humana desejável e um meio ambiente ideal" (Carvalho, 2001, p. 37). Assume-se, ademais, o campo ambiental como constituído por dupla dimensão, uma estruturada e outra estruturante, de tal modo que se este exerce algum poder estruturante o faz somente por se encontrar estruturado (Carvalho, 2001). Nesse ínterim, a fim de compreender as ênfases e as configurações assumidas pelas práticas em educação, concentramos os esforços de análise justamente na articulação entre essas duas dimensões - aqui representadas, respectivamente, pelas políticas e aparatos públicos, de uma parte, e pelos agentes atuantes no campo, de outra.

Educação \& Realidade, Porto Alegre, v. 39, n. 2, p. 535-556, abr./jun. 2014.

Disponível em: <http://www.ufrgs.br/edu_realidade> 
Sujeitos, Políticas e Educação Ambiental na Gestão de Resíduos Sólidos

Por fim, faz-se importante ressaltar que, apropriando contribuições de Isabel Carvalho, procuramos tematizar a educação ambiental como via compreensiva de acesso ao ambiente. Em tal prática, que se dá “[...] orientada para a problematização dos diferentes sentidos, interesses e forças sociais que se organizam em torno das questões ambientais” (Carvalho, 2003, p. 117), adquirem relevo a contextualização histórica das relações sociais nas quais nos inserimos e através das quais nos constituímos sujeitos.

Trata-se, dessa forma, da adoção de uma postura voltada à escuta e à imersão em campo, atenta aos “[...] códigos simbólicos que regem a vida cotidiana, os sistemas políticos, as formas de produção e de consumo" (Lisboa, 2009), para que estes sejam apreendidos e tornados objetos de reflexão: a relação construída pelo sujeito com seu contexto de ação e a forma como interpreta tal vinculação (quando mediada por noções comuns ao processo de ambientalização) ${ }^{5}$ configura a educação ambiental analisada aqui. A pesquisa organiza-se como exercício de compreensão dos processos pelos quais produzimos o 'ambiente' como espaço sociocultural de ação e potencialidade para organização da vida.

\section{A Constituição de uma Cadeia Produtiva: ambiência para uma política pública em reciclagem}

Por volta dos anos 1960 e 1970, em função da emergência e da consolidação do movimento ecologista a nível mundial e da consequente ampliação dos debates acerca dos limites do modelo de desenvolvimento capitalista, o universo simbólico a partir do qual a gestão dos resíduos vinha sendo pensada - centrado até então num ideal de saúde pública e na busca pelas melhores formas de se atingi-lo - sofre uma significativa reformulação. De acordo com Oliveira (1995), este é o momento da chamada "ecologização" das políticas de limpeza urbana. $\mathrm{Na}$ região sul do Brasil, por exemplo, observa-se a ampliação (e, em alguns casos, até mesmo o deslocamento) do foco dessas políticas que passam a ser orientadas não apenas à promoção e manutenção da saúde pública, mas também à proteção da natureza: “[...] o lixo passa a ser visto como causador de poluição ambiental, exigindo um controle do efeito por ele causado sobre o meio" (Oliveira, 1995, p. 56).

Em exemplo consoante, na análise que faz dos conflitos sociais envolvendo a Companhia Siderúrgica Nacional (CSN) na cidade de Volta Redonda no Rio de Janeiro, Lopes (2006) procura caracterizar o transcorrer de um processo histórico de passagem de intensos conflitos centrados em questões trabalhistas (situados, portanto, no "interior da fábrica”) para uma situação de conflito mais ampla, neste caso da cidade contra a fábrica, por motivos relacionados à degradação das condições ambientais. Entre um extremo e outro dessa escala, dá-se, nas palavras do autor, a "descoberta da poluição", elemento novo que implica 
a complexificação da trama de relações, mediante a entrada em cena de outros grupos profissionais (técnicos e experts) e certo deslocamento do foco sobre o qual se davam as disputas iniciais.

Nesse sentido, a emergência de uma questão ambiental como nova fonte de legitimidade junto aos conflitos sociais poderia ser lida como indício da consolidação de um campo social específico, neste caso, de um campo ambiental, bem como do desenrolar um processo histórico que, assim como outros processos similares, “[...] implica simultaneamente transformações no Estado e no comportamento das pessoas” (Lopes, 2006, p. 36).

Em seu esquema, faz-se importante ressaltar, Lopes (2006) relaciona essas transformações aos seguintes fatores: ao crescimento da importância da esfera institucional do meio ambiente nas últimas três décadas; aos conflitos sociais locais e aos seus efeitos na interiorização de novas práticas; à educação ambiental como novo código de conduta individual e coletiva; e, por fim, à questão ambiental como nova fonte de legitimidade e de argumentação nos conflitos.

A reciclagem dos resíduos sólidos urbanos, por seu turno, apesar de figurar como horizonte a ser alcançado pelo menos desde a década de setenta, torna-se uma aposta pública para a resolução dos problemas ambientais e sociais somente no início dos anos 1990. Concebida, até esse momento, como técnica pouco produtiva e, portanto, inviável em larga escala, a reciclagem de resíduos sólidos havia se restringido a algumas experiências-piloto (Oliveira, 1995) que, de modo geral, procuravam dar conta do crescente contingente de pessoas que viviam do lixo.

Em alguns casos, as primeiras associações de catadores surgem antes mesmo das iniciativas do poder público para a implantação da coleta seletiva. Este é o caso de Porto Alegre, cuja implementação municipal da coleta foi iniciada oficialmente nos anos 1990, abarcando o que, em um primeiro momento, se apresentava como "radicalização da opção pelos pobres" vinculada a iniciativas assistenciais religiosas (Martins, 2003), e a convertendo em "política inovadora em matéria de limpeza urbana” (Oliveira, 1995, p. 115). Observa-se, neste caso, significativa alteração da matriz discursiva desde a qual se formulam os enunciados sem que isso, ao menos em um primeiro momento, implique modificações substanciais nas relações da sociedade com seus resíduos.

Vinculada aos debates acerca da produção e destinação de lixo, temos, pois, a emergência de uma cadeia produtiva organizada em torno da reciclagem de materiais oriundos dos descartes urbanos, fato este associado à recente organização de cooperativas e associações de catadores. Embora encontremos ocorrências na primeira metade da década de 1990, a formalização jurídica de tais coletivos concentra-se ao final deste decênio e ao longo dos anos 2000.

Nesse sentido, tendo também em mente a evolução das políticas públicas e da legislação específica durante este período, as informações 
Sujeitos, Políticas e Educação Ambiental na Gestão de Resíduos Sólidos

obtidas nas entrevistas indicam que os coletivos foram formados a partir da condição comum de vulnerabilidade social e acesso aos resíduos como atividade de subsistência. Configurada esta situação, entravam em cena parcerias no apoio à organização coletiva e reivindicação de condições de trabalho, sendo o Estado mobilizado para atendimento dos grupos de catadores. Dito de outro modo, o poder público, em parceria com organizações civis diversas, passa a articular o trabalho de catadores e recicladores (nomeado como 'iniciativa de geração de renda') e a necessidade de gestão dos volumes de resíduos produzidos, particularmente, nos centros urbanos (como exemplo da citação abaixo).

[...] já faz uns cinco anos que o município tem parceria com as associações de reciclagem [...] como uma atividade de inserção social, de autoestima e dignidade do cidadão, junto com a igreja e depois o município foi criando políticas de apoio às associações de reciclagem. [...] (Gestor público - Meyer; Fischer; Stephanou, 2010, p. 43).

[...] Nós começamos aqui em 94, vai fazer 15 anos agora em novembro [...] No início tava feio aqui, não tinha luz, não tinha água, não tinha nada. Não tinha elevador pra carregar os fardos, nos tinha que carregar tudo a muque, levamos um mês pra fazer uma carga de papelão [...] Sempre queimavam o lixo antigamente [...] Tinha parado, porque o prefeito,... multaram o prefeito. Tinha que dá cesta básica, não sei... porque o mato ia tudo lá pro centro, queimava aqui dia e noite [...] Roque trabalhou dez anos ali na prefeitura de meio ambiente ali. O prefeito que fez a proposta toda ele veio pra cá [...] (Catador - Dois Irmãos/ RS - Meyer; Fischer; Stephanou, 2010, p. 43).

Assim, a constituição de uma cadeia produtiva para a reciclagem se consolida no entrelaçamento de discursos e condições históricas relativamente recentes. Podemos considerar a participação dos movimentos e discursos ecológicos e ambientalistas a estabelecer e ressignificar pautas relativas ao desenvolvimento capitalista (Lopes, 2006) que, associadas à problemática pública da gestão dos volumes de descartes que geramos, dispõe a demanda por soluções sustentáveis à sociedade como um todo e, especialmente, aos gestores públicos.

Integra-se a essa demanda o trabalho de catadores e associações de recicladores (de forma mais ou menos organizada politicamente) ${ }^{6}$ que, orientado à subsistência desde condições e trajetórias historicamente precarizantes, articula-se atuando especialmente na triagem e comercialização dos resíduos recicláveis (como tentamos explicitar nas citações abaixo).

Nossos diálogos com catadores sinalizaram que o envolvimento com a reciclagem se apresenta como a culminância de experiências de trabalho informais. As trajetórias narradas estão perpassadas por informalidade dos vínculos de trabalho, condições precárias de labuta e 
movimentos migratórios familiares em busca de melhores condições de vida. Depoimentos colhidos na pesquisa ilustram o quadro que acabamos de delinear:

[...] Olha, eu nasci em Minas Gerais, lá na cidade maior é Portiguara, mas onde foi tirado os meus documentos foi Campestre, uma cidadezinha pequena. Ai a gente veio pra cá, na Fazenda Itaúna, em 1947, tinha 3 anos de idade. Ai eu fiquei até a idade de 11 anos, quando eu fui para um sítio tocar plantação [...] (Catador - Londrina/PR - Meyer; Fischer; Stephanou, 2010, p. 44).

[...] Eu comecei a trabalhar na fazenda com meu tio de pião eu tinha dez anos, já trabalhava. Foi por ali que eu fui aprendendo com a vida [...] Vim com dezenove anos [para Porto Alegre], em 1970. Aí, aqui eu comecei, cheguei aqui e comecei nas obras, serviço arranjado pelo meu cunhado e irmão, comecei nas obras, de servente, porque eu não sabia [...] (Catador - Porto Alegre/RS - Meyer; Fischer; Stephanou, 2010, p. 44).

Ao longo do século XX, a formação socioeconômica da Região Sul do Brasil passou da produção pecuarista para a agrícola, e desta para a industrial, com destaque ao beneficiamento de alimentos, à fabricação têxtil em algumas partes de Santa Catarina e à indústria química no Paraná. Além disso, as regiões de colonização no Rio Grande do Sul e Santa Catarina apresentaram considerável diversificação produtiva industrial. Neste ínterim, os processos de automação chegam também à agricultura (especialmente, a partir dos anos 1960-1970), com o incremento da produção de soja (Lagemann, 1998).

A automação no campo dispensou considerável número de trabalhadores, os quais passam a buscar alternativas de ocupação e renda nos centros urbanos. Ao processo de êxodo rural, que constatamos de maneira distinta em cada estado abrangido pelo estudo, associam-se os processos de automação e reestruturação produtivas fabris, intensificados nos anos 1990, ampliando a margem de desemprego estrutural e, ao que parece, reforçando a informalidade dos vínculos de trabalho (Montali, 2000).

Ainda que tenhamos melhoria dos índices de crescimento e emprego no Brasil nos últimos anos ${ }^{7}$, no que tange à realidade dos sujeitos com quem dialogamos, sua condição de informalidade não foi alterada, sendo sua participação construída na manutenção histórica de atividades precarizantes que integram e apoiam o funcionamento da produção capitalista, como são exemplos subcontratações na construção civil, nas lavouras de café e, também, a ação de catadores.

[...] É. Que daí a gente, daí foi escasseando a vendeção de capim e nós viemos morar mais pra cá. Daí ele começou a trabalhar em obra, que era carpinteiro. Sempre na luta!

Educação \& Realidade, Porto Alegre, v. 39, n. 2, p. 535-556, abr./jun. 2014.

Disponível em: <http://www.ufrgs.br/edu_realidade> 
Antes era com porco, né. A gente criava, daí ali já tirava o papel, a latinha, começamos assim. Aí depois proibiram; foi só com papel. Que se terminaram [...] (Catador - Porto Alegre/RS - Meyer; Fischer; Stephanou, 2010, p. 45).

[...] Mas eu já tenho vários currículos ai, soltei muitos currículo mas teve gente que teve muito preconceito pelo lugar aonde a gente mora, como a gente se veste, pela aparência, que é o que mais importa hoje no mercado de trabalho. Então eles reparam muito isso, muito a aparência da pessoa, se o lugar onde a pessoa mora sai muito na reportagem eles já não gostam, então tudo isso já conta. E é difícil, bem difícil. Só que é bem difícil pra gente ta arrumando um serviço assim.[...] (Catador - Londrina/PR - Meyer; Fischer; Stephanou, 2010, p. 45).

Por conseguinte, podemos afirmar que a constituição da cadeia produtiva para a reciclagem se beneficiou de um processo histórico de inclusão precarizada (Martins, 2002) que, conforme as peculiaridades econômico-produtivas de cada região, vem gerando um contingente de trabalhadores migrantes com reduzida escolarização/qualificação, que transita em busca de subsistência conforme lhes são fechadas as portas nos locais em que vivem e nos espaços em que trabalham.

\section{Configuração da Coleta Seletiva: relações e ações para a reciclagem}

Antes de caracterizarmos as ações dos principais sujeitos atuantes nos aparatos municipais de reciclagem, cabe descrever como usualmente vem sendo operacionalizado o processo de coleta seletiva nas cidades visitadas.

De modo geral, a coleta seletiva nos municípios consultados se estrutura da seguinte maneira: realiza-se a busca domiciliar e/ou comercial dos resíduos mediante a ação de aparatos públicos, de empresas privadas ou mistas terceirizadas, ou da catação dos próprios recicladores (em acordo com as prefeituras); o material coletado é entregue para associações de catadores, que efetuam uma primeira etapa do tratamento dos resíduos sólidos urbanos - triagem, prensagem e enfardamento, conforme os equipamentos que possuem; e, depois, os coletivos comercializam o resultado de seu trabalho, vendendo normalmente para intermediários (chamados atravessadores). Os rejeitos da triagem são destinados a aterros sanitários ou mesmo a lixões, acompanhando resíduos orgânicos produzidos.

\section{A Ação do Poder Público Municipal}

Interferem na qualidade do trabalho e na renda gerada pelas associações de triagem as parcerias que constituíram ao longo de sua atu- 
ação. Podemos destacar a presença do poder público municipal. Junto a este, geralmente conquistam instalações físicas, equipamentos e matéria-prima.

\section{Gráfico 1 - Parcerias Recentes das Associações}

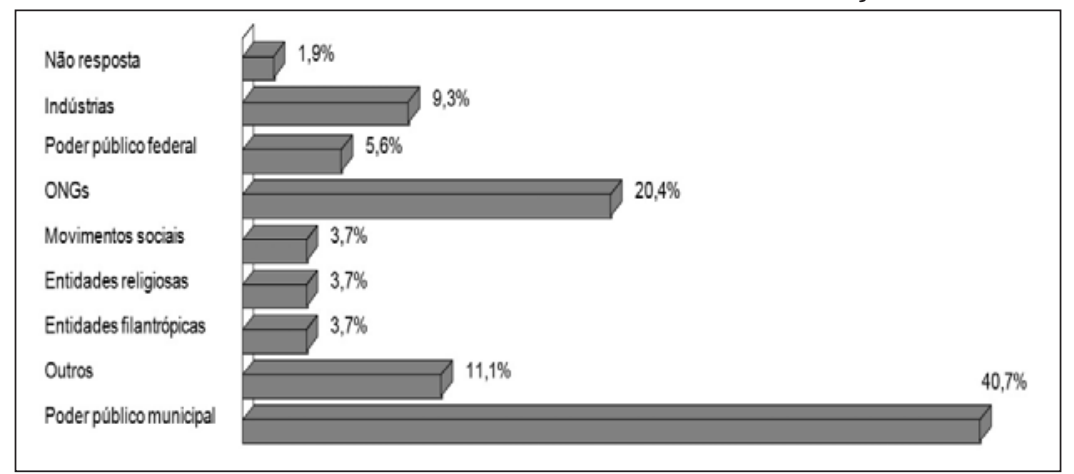

Fonte: Estudo do Perfil Socioeducacional dos Catadores de Materiais Recicláveis da Região Sul (SECAD/MEC - UFRGS).

Se compararmos, então, os dados acima com as informações relativas às parcerias no início das atividades das unidades de triagem, permanecem as menções à participação do poder público municipal, dado congruente com sua atribuição histórica na destinação dos resíduos (identificada também no gráfico abaixo). Neste sentido, devemos assinalar a importância do poder público na organização da cadeia produtiva, na contratação de catadores e na institucionalização do campo de ação destes trabalhadores.

Gráfico 2 - Recebimento do Material pelas Associações

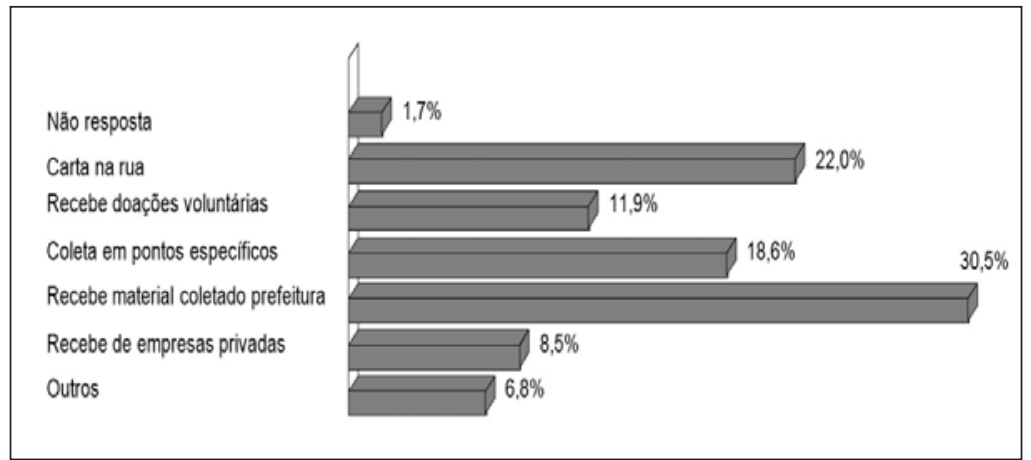

Fonte: Estudo do Perfil Socioeducacional dos Catadores de Materiais Recicláveis da Região Sul (SECAD/MEC - UFRGS).

No gráfico 2, merece destaque a proporção de materiais recebidos por intermédio da coleta realizada pelas prefeituras, indicando a importância da gestão pública na organização desse mercado. Constituem 
Sujeitos, Políticas e Educação Ambiental na Gestão de Resíduos Sólidos

exceção as unidades de Londrina/PR e Blumenau/SC, mas mesmo essas podem ser englobadas no perfil citado se nos dedicarmos à análise de suas particularidades.

Em Blumenau/SC, a unidade mantida pela prefeitura se encontrava em um momento de transição, em que os funcionários seriam demitidos para a constituição de uma associação única na cidade (logo, sem vínculos empregatícios e direitos trabalhistas), abarcando ainda integrantes de outro coletivo, cuja atuação se caracterizava pela catação de rua. Os planos da gestão municipal fortaleceriam, então, o recebimento por coleta pública, admitindo, no entanto, que os catadores mantivessem também sua atuação anterior (na rua), já que a coleta seletiva municipal não atendia toda a cidade.

[...] o Serviço Autônomo Municipal de Água e Esgoto (SAMAE) vai ceder as instalações que compreende um pavilhão aqui de $750 \mathrm{~m}^{2}$, com esteira, com todos os equipamentos necessários para a reciclagem, prensas separador de vidro, etc. E vamos ceder também quatro caminhões com motoristas e combustíveis e nos estamos contratando uma associação, a associação RECIBLU, que é a associação dos catadores e carrinheiros de Blumenau para trabalhar com a gente. É um contrato não oneroso, eles recebem os caminhões com os motoristas com a estrutura e o trabalho deles é entrar com a mão de obra para a triagem e a venda. [...] A cada 100 toneladas de lixo que a associação retira das ruas através da triagem, o SAMAE tem um ganho de aproximadamente $\mathrm{R} \$ 17.000$, por que custa para o SAMAE R $\$ 170,00 / \mathrm{T}$ a coleta e o destino final do lixo $[. .$.

[...] ai depende da RECIBLU. Então eles têm três meses para colocar 28 pessoas. Com 28 pessoas o SAMAE conseguia fazer 100 toneladas por mês [...] Então eles também vão poder trabalhar com o carrinho, eles vão poder comprar o material do carrinheiro de Blumenau, coisa que a SAMAE não podia fazer [...] (Gestor público - Meyer; Fischer; Stephanou, 2010, p. 49)

De outra parte, em Londrina/PR, onde a catação é significativa como fonte de matéria-prima para as unidades de triagem, constatamos que a prefeitura destina aos catadores parte da coleta seletiva, proporcionando uma espécie de trabalho compartilhado. Neste sistema, os integrantes das associações se incubem da busca dos resíduos nos domicílios e ruas de bairros previamente zoneados pelo poder público, deixando o montante em pontos específicos (chamados bandeiras), para que caminhões (do município) façam o recolhimento e translado até as sedes das associações.

Assim, podemos observar certa ampliação dos serviços prestados por recicladores, abrangendo não só a triagem e comercialização, sem 
que percebam efetiva compensação pecuniária. No caso de Blumenau/ SC, constatamos uma espécie de retrocesso na garantia de direitos trabalhistas inclusive, uma vez que o aparato público praticamente se desonera do serviço.

Situa-se, então, a discussão a respeito das diferentes responsabilidades e benefícios relacionados à atividade de reciclagem, pensada aqui como política pública. De modo mais específico, o que está em jogo é a prestação de um serviço urbano essencial por parte dos catadores, que não nos parece devidamente reconhecido pelo Estado e pela opinião pública dadas as condições de subcontratação e/ou precariedade e periculosidade com que normalmente o trabalho é realizado nas associações de reciclagem ${ }^{8}$.

\section{A Ação dos Atravessadores}

Ao que tudo indica, outro elo importante na manutenção da cadeia produtiva é a comercialização do material processado nas unidades de triagem. A maioria dessas unidades vende o resultado de seu trabalho para intermediários, comumente chamados de atravessadores. Considerando que, de forma geral, as associações não logram a produção mensal necessária para venda direta à indústria de beneficiamento, estas estabelecem acordos de fornecimento relativamente duradouros com empresas privadas que compram e acumulam material suficiente para tal negociação.

Esta condição amplia a margem de exploração do trabalho de recicladores, mediante redução dos preços dos materiais que comercializam. Observamos que no conjunto das unidades pesquisadas não se apresenta, nos discursos e projetos coletivos, a alternativa da articulação entre associações de modo a interferirem nas práticas de comercialização, desde a negociação coletiva com o atravessador até a definição do valor de venda dos resíduos processados. De outra parte, as práticas de comercialização normalmente não são alvo de intervenção estatal, seja porque as associações evitam tal participação, seja por suposta desobrigação do poder público, ainda que este conheça e, em alguns casos, admita a ação de intermediários, como exemplificado na citação abaixo.

[...] Na expo feira quando a gente trabalhou junto com eles [catadores de rua], eu acompanhei inclusive a venda do material [...] Olha a diferença, então a gente conseguiu, batalhamos junto com as recicladoras [atravessadores], trouxemos, fizemos reuniões com as recicladoras, que elas que compram os materiais deles [...] E aí um dos donos de recicladoras, disse - não a gente vai... conseguiram contato, mediar preço, a gente vai bancar o valor pra... até pra apoiar, incentivar eles [...] (Gestor público - Meyer; Fischer; Stephanou, 2010, p. 50).

Educação \& Realidade, Porto Alegre, v. 39, n. 2, p. 535-556, abr./jun. 2014. 
Sujeitos, Políticas e Educação Ambiental na Gestão de Resíduos Sólidos

\title{
A Ação das Associações de Catadores
}

Mais de $79 \%$ dos grupos são compostos por menos de 30 associados, dados que, contemplados em relação às condições relacionais de coleta e comercialização mencionadas acima, sugerem a existência de limitações físicas, financeiras e organizacionais para o funcionamento de coletivos maiores.

A realidade encontrada durante a pesquisa sinaliza que as relações e práticas consolidadas tanto na contratação das unidades quanto na comercialização do que estas produzem, vêm estabelecendo condições de trabalho e níveis de renda insatisfatórios e insuficientes, os quais, na maioria dos casos, colaboram na manutenção da vulnerabilidade social desses trabalhadores.

Considerando o desenho das cadeias produtivas para a reciclagem elaborado desde a investigação, cumpre, ainda, registrar as estratégias construídas pelos catadores frente ao contexto que se lhes apresenta, evitando vitimizá-los na análise das relações sociais em que participam. Em que pesem (e em articulação) as relações de poder enunciadas nos parágrafos anteriores, temos de acrescentar, também, a menção aos laços de solidariedade estabelecidos entre associações e atravessadores: na forma de exclusividade de fornecimento e contrapartida de um pagamento seguro; ou, ainda, em empréstimos e adiantamentos que os intermediários garantem aos recicladores, os quais, atuando sob situações instáveis e adversas, encontram em quem os explora apoio imediato.

\begin{abstract}
[...] Ele [o marido] era catador antes, aí ele conseguiu crescer; tava comprando de uns dez, quinze grupo. Até quinze grupo! Porque tinha um dez, agora começou a cooperativa, e ele tem a documentação. Aí a gente sugeriu de passar o nosso papelão pra ele e descontar só o valor da nota [...] (Recicladora - Londrina/PR - Meyer; Fischer; Stephanou, 2010, p. 51).

[...] Vendemos pra Porto Seguro [atravessador], pra ASCALIXO [associação]. A ASCALIXO que paga mais um pouco, mas a ASCALIXO teve falida, recém ela ta levantando, ai ficou pra Porto Seguro [...] (Gestor associação - Rio Grande/RS - Meyer; Fischer; Stephanou, 2010, p. 51).
\end{abstract}

Por vezes, observamos que os lugares ocupados pelos sujeitos possuem delimitações flexíveis, de modo que as fronteiras em relação aos papéis exercidos são difusas. Encontramos casos em que associações de recicladores atuam como atravessadores; deparamo-nos com trabalhadores que, depois de atuarem como catadores, passaram a atravessadores de associações nas quais trabalhavam parentes, sendo que, ademais, apoiavam tais unidades oferecendo eventualmente translado para alguns de seus integrantes. 
Assim, consideramos que os laços de solidariedade que se configuram nas práticas de coleta seletiva municipais extrapolam a delimitação estanque de papéis e, além disso, colaboram na manutenção das relações sociais constituídas (em níveis mais ou menos intensos de exploração).

Em nosso entendimento, ao naturalizarem e legitimarem tais práticas na consecução de suas estratégias cotidianas, os catadores (e também os demais sujeitos de diálogo) constroem a configuração da cadeia produtiva para a reciclagem e da política pública na área: ao que parece, não se trata somente de questões econômicas e materiais, mas sim de redes sociais e culturais de manutenção da sobrevivência e convívio na relação com o contexto, na produção do ambiente.

\section{Gerenciamento e Educação Ambiental: práticas dos aparatos públicos}

O Estado, como entidade representativa, tem se responsabilizado social e historicamente por encaminhar o tratamento dos descartes e resíduos produzidos pelos cidadãos. A articulação do poder público com a prática de reciclagem o levou a exercer a planificação e institucionalização de uma cadeia produtiva que associa projetos de geração de trabalho e renda para populações vulnerabilizadas e a necessidade (econômica e ecológica) de triagem e reaproveitamento de parte dos resíduos gerados na vida contemporânea.

Por pressão de agendas ambientalistas e em função da gradual inserção destas entre as prioridades da administração pública, a máquina estatal passa a implementar políticas de gestão de resíduos, integrando, inicialmente, atendimentos localizados, evidenciados por reivindicações comunitárias ou por pleitos do próprio aparato público ${ }^{9}$.

Especialmente a partir da década de 1970, observa-se que a gestão pública de resíduos tem se dado na tensão entre, de um lado, temas ambientais tomados como recomendações e exigências previstas em legislação e, de outro, prioridades de crescimento econômico-produtivo locais e preocupações financeiras e fiscais das administrações municipais. Não raro, identificamos depoimentos de gestores imersos, ou mesmo imbuídos, em considerável pragmatismo e produtivismo, quando a relação com associações de triagem passa fundamentalmente pela pressão para incremento dos montantes reciclados, pelo aumento do número de associados (supostamente inseridos em iniciativas de inclusão social), ou a ampliação das atribuições dos catadores.

[...] estamos exigindo produtividade deles, [que] trabalhem dois turnos, que sexta-feira a tarde já era churrasco, não trabalhavam sábado. Tem que entrar no ritmo de produção. Até porque toda uma parte do serviço que eles faziam bruto e cansativo que era puxar carrinho de baixo

Educação \& Realidade, Porto Alegre, v. 39, n. 2, p. 535-556, abr./jun. 2014. 
Sujeitos, Políticas e Educação Ambiental na Gestão de Resíduos Sólidos

de chuva, sol [...] hoje eles não fazem mais. Então eles têm tempo suficiente pra triar todo esse material. É uma questão mais de organização. E pra isso nós temos uma consultoria que foi feita com Banco do Brasil e VONPAR [...] (Gestor público - Meyer; Fischer; Stephanou, 2010, p. 54).

De forma geral, os administradores públicos entrevistados ${ }^{10}$ falaram das potencialidades da atividade de reciclagem para inclusão social e mencionaram seus planos de qualificação das condições de trabalho dos catadores. No entanto, tais considerações não os impediu de observar tais investimentos sob propósitos de qualificação do serviço e de redução dos custos para a máquina pública. Todavia, sem desconsiderar a relevância de tais objetivos, vale ressaltar que, até então, as metas dos aparatos de reciclagem pesquisados vêm se dando associadas à exploração do trabalho das associações de recicladores: a articulação entre geração de renda para populações vulnerabilizadas (sob as condições precarizantes que presenciamos) e prestação de um serviço público essencial pode ser financeiramente conveniente, mas tem corroborado, social e politicamente, situações de informalidade e desigualdade.

Não raro, a ação estatal vem acompanhada de ações que pendem à institucionalização dos catadores, instrumentalizando-os corporativamente em serviços que eles já realizavam como estratégia de sobrevivência. E isto sem significativa mudança em seus ganhos de renda.

[...] Temos também um trabalho também com os catadores avulsos que estão na rua, esse trabalho ainda é pequeno, que começou o ano passado com o cadastramento de catadores. Por quê? Porque nos temos lá na área comercial, lá em volta do calçadão, um grande índice de catadores coletando nas lixeiras, então, propomos uma parceria com a CDL, que é a câmara de dirigentes lojistas [...] CDL ofereceu os uniformes, nós fornecemos o crachás. A CDL fez o trabalho de informação, na realidade de educação ambiental junto ao lojista, todo esse apoio também com parceria da secretaria. Então o que se fez a partir do momento que o catador estava cadastrado nesse programa que é denominado um programa de projeto de agentes ambientais. Se repassava o catador cadastrado e identificado para o lojista [...] (Gestor público - Meyer; Fischer; Stephanou, 2010, p. 55).

[...] a cadeia produtiva deste trabalho de reciclagem hoje é gerida pela secretaria de desenvolvimento econômico de trabalho e emprego. [...] então nós percebemos na cadeia produtiva de reciclagem uma fonte de emprego e renda e uma iniciação correta de resíduos e também uma geração de matéria prima pra indústria [...] (Gestor público Meyer; Fischer; Stephanou, 2010, p. 55).

Noutras ocasiões, verificamos ações estatais mais incisivas, na tentativa de regular o mercado de resíduos, apoiando a articulação das 
unidades e a conquista de melhores preços. O que não parece se alterar, porém, é certa perspectiva economicista que acompanha as ações em análise. Nos depoimentos dos gestores públicos, a atenção se volta, via de regra, às repercussões aos sistemas econômicos locais, isto é, ao fato de como a reciclagem pode reverter em ampliação da produtividade para tais sistemas. E, presidindo os objetivos e argumentos explicitados, assoma certa "ótica", orientando as práticas desde princípios de eficiência e eficácia produtivas.

Além disso, com a constituição de uma cadeia produtiva e, na sequência, a atribuição e consolidação de valor econômico ao material reciclável (em escala mais ampla que aquela experimentada inicialmente pelos catadores de rua), tende-se a verificar expansão do número de agentes mobilizados para a aquisição, tratamento e comercialização dos descartes. Constituem-se em empresas privadas de porte variado que, muitas vezes, interferem na coleta, garimpando e interceptando os produtos de melhor valor no mercado e exercendo certa concorrência pelas atividades mais lucrativas.

O quadro esboçado acima situa a política de gestão de resíduos implementada nas cidades pesquisadas como um processo congruente com a manutenção do sistema de produção capitalista. Conforme entendemos, a prática da reciclagem, propalada por seus benefícios aos problemas ambientais, paradoxalmente, tem se organizado em coerência com padrões de consumo e descarte que produzimos, sem crítica às bases insustentáveis de relação com o ambiente em que estes vêm se estruturando.

\section{Neste Ínterim, as Práticas em Educação Ambiental}

Quando questionados sobre as atividades de educação ambiental, os administradores públicos direcionaram suas respostas às ações de sensibilização sobre a importância da preservação do meio ambiente e à orientação sobre a coleta seletiva implantada nos municípios, destinadas particularmente às escolas de suas redes de ensino.

[...] Então nós temos um projeto primeiro com toda a população, investimento em escolas, em alunos da rede municipal na preparação de material e isso tudo hoje são as pessoas que fazem isso [...] (Gestor Público - Meyer; Fischer; Stephanou, 2010, p. 56).

Interessa observar que as atividades elencadas pelos gestores públicos têm, sobretudo, um caráter normativo, focado na prescrição de comportamentos e ações ${ }^{11}$. Não obstante, reconhecendo a importância dessas medidas, podemos aventar a ampliação do entendimento sobre as práticas educacionais, refletindo sobre a dimensão e as repercussões educativas das ações atualmente estruturadas junto a catadores, atravessadores, cidadãos, observando de maneira relacional a forma como nos educamos em nossa interação e pertencimento ao ambiente.

Educação \& Realidade, Porto Alegre, v. 39, n. 2, p. 535-556, abr./jun. 2014. 
Sujeitos, Políticas e Educação Ambiental na Gestão de Resíduos Sólidos

Para tanto e a título de contextualização, convém retomar algumas das proposições de José Sérgio Leite Lopes sobre o processo de ambientalização dos conflitos sociais. De acordo com o autor, antecedendo e acompanhando nos últimos 25 anos a pertinente inquietação das forças ambientalistas com os paradoxos do desenvolvimento econômico, é possível detectar no Brasil, assim como em outros países, a existência de um processo "[...] de invenção, consolidação e avanço da temática ambiental, que se manifesta também por conflitos, limitações internas, assim como por reações, recuperações e restaurações" (Lopes, 2006, p. 32). Um jogo mediante o qual se dá a gênese e a consolidação de um campo social específico no qual se cruzam e transformam trajetórias de grupos e sujeitos os mais variados.

Especificamente no que se refere ao papel da educação ambiental no desenrolar desses processos, ele aparece definido por Lopes (2006) como o de fornecedora de informações e códigos de comportamento correto, numa comparação direta aos manuais de etiqueta analisados por Norbert Elias ${ }^{12}$ quando da caracterização do processo civilizador no ocidente. Sob essa perspectiva, a educação ambiental aparece vinculada a uma moral normatizadora/normalizadora ao mesmo tempo em que a uma matriz explicativa, em grande medida oriunda da tradição das ciências naturais. A visão que se constrói aqui é a de uma educação ambiental como transmissão de conhecimentos e normatização de condutas. Um papel específico e restrito no conjunto de eventos e relações constituintes de um campo ambiental e que acaba por limitar, assim nos parece, suas possibilidades transformadoras, tanto para aqueles sujeitos aos quais se dirige, quanto aos indivíduos e grupos que a assumem como prática pedagógica.

Por outro lado, seguindo de perto Carvalho (2001; 2003; 2004; 2005), abre-se a possibilidade de tematizar a educação ambiental como via compreensiva de acesso ao ambiente ${ }^{13}$. Nesse esquema, diferentemente do anterior, a práxis educativa aparece "[...] orientada para a problematização dos diferentes sentidos, interesses e forças sociais que se organizam em torno das questões ambientais" (Carvalho, 2003, p. 117). Desvinculada de uma moral normativa, que prescreve valores e comportamentos a serem reproduzidos e impostos a diferentes configurações espaciais (Garcia, 2001), a educação ambiental assume aqui um caráter essencialmente compreensivo. Carvalho propõe, nesse ínterim, que se compreenda a experiência do educador ambiental como a de "[...] um intérprete de seu contexto, ao mesmo tempo em que é um sujeito interpretado" (Carvalho, 2003, p. 30). Uma perspectiva que ressalta a reciprocidade inerente ao encontro (interpretar e ser interpretado, conhecer e dar-se a conhecer) e na qual compreensão, interpretação e ação já não podem mais ser dissociadas. Nas palavras da autora:

Essa perspectiva implica ainda a recusa da dicotomia entre o plano do pensamento e o da ação. Os sentidos produzidos por meio da linguagem são a condição de possibili- 
dade do agir no mundo. Não há ação possível num vácuo de sentido. Toda ação decorre de certa compreensão/interpretação, de algo que faz sentido num universo habitado por inúmeras chaves de sentido. Dessa forma, assim como interpretar não seria um ato póstumo e complementar a compreensão, agir não corresponderia à consequência - como desdobramento, ato segundo ou posterior à reflexão -, mas a ação estaria implicada no ato mesmo de compreender/interpretar (Carvalho, 2003, p. 31).

Não há dúvidas que a concepção vigente de educação ambiental entre os gestores públicos consultados durante a investigação que conduzimos aproxima-se muito mais daquela mencionada por Lopes (2006) do que a proposta por Carvalho (2003). Ademais, mesmo na condição de "fornecedora de informações e códigos de comportamento correto”, a educação ambiental conduzida junto aos aparatos de coleta seletiva e reciclagem nos três estados da região sul parece ter ainda muito que avançar. De modo especial, porque tende a desconsiderar, no conjunto de elementos que também a constituem enquanto prática formativa, as singulares trajetórias de vida dos sujeitos aos quais se dirige, bem como suas condições concretas de existência e suas relações com a materialidade que o cerca. Nesse sentido, nosso itinerário dessa pesquisa tem sugerido algumas possibilidades de abordagem do problema, compreensivas acima de tudo, que nos inspiram e motivam na busca de medidas educativas junto a catadores, sujeitos com quem dialogamos mais intensamente.

Em campo, por exemplo, entre observações e conversas com homens e mulheres catadores, a prática de narrar trajetórias tem configurado uma atividade reflexiva sobre as experiências de vida, ora destacando vivências significativas, ora proporcionando comentários acerca do contexto. Destarte, a narrativa (oral, escrita ou imagética) ${ }^{14}$, além da coleta de informações, potencializa um processo educativo que, consideramos, começa pela reconstrução das interpretações dos sujeitos sobre seu lócus desde os caminhos que percorreram.

\section{Considerações Finais}

Observamos a promoção da reciclagem entre técnicas ecologicamente adequadas para o tratamento do lixo. Esta parece seguir, no entanto, destituída de uma crítica sobre si mesma e, neste caso, sobre suas próprias condições de possibilidade e incremento. As atividades de coleta seletiva e reciclagem congregam um contingente crescente de pessoas em inclusão precária, mulheres e homens em tarefas insalubres e socialmente depreciadas.

Nesse sentido, as práticas de educação ambiental relativas à gestão de resíduos, incluindo a coleta seletiva e a reciclagem, parecem se situar no conjunto de artifícios pedagógicos predominantemente nor- 
Sujeitos, Políticas e Educação Ambiental na Gestão de Resíduos Sólidos

mativos. Para além de repercussões educativas voltadas ao controle de condutas, que poderíamos supor na ação que procura prescrever ações aos sujeitos, aventamos, aqui, certa ocultação das relações que organizam as políticas e práticas de reciclagem, produtoras também de ações e resultados formativos, consolidadas em tomadas de posição cotidianas constituintes da interação com o Outro e com o ambiente.

Se tomarmos as narrativas construídas com os catadores, por exemplo, percebemos que estes parecem reconhecer e verbalizar o suposto valor de sua atividade, como um serviço prestado ao meio ambiente. Enunciam, por outro lado, o desejo de um trabalho distinto e o sentimento de desvalorização do exercício da reciclagem. O trabalho de reciclagem, na maioria dos casos, é narrado como uma alternativa de sustento, uma opção desde a subsistência cujas aprendizagens direcionam-se, sobretudo, aos saberes técnico-operativos da triagem e comercialização de resíduos.

A necessidade de sobrevivência, o aumento na renda, a melhoria na qualidade de vida e o desejo de inserir-se também no mercado de consumo constituem prioridades para estes sujeitos, sendo a relação com o discurso ambiental, na maioria das vezes, instrumentalizada na medida de suas necessidades. As práticas de educação ambiental, frente às outras condições que estruturam o espaço de ação de catadores, apresentam-se como iniciativas pouco significativas, epidérmicas e, por isso, politicamente fragilizantes, ao não partir das condições em que os sujeitos constroem, efetivamente, sua relação com o ambiente e ao não questionar as relações de poder em jogo.

Ainda que admitamos a relevância das atividades de educação ambiental, é preciso frisar que as atividades e relações da cadeia produtiva da reciclagem vêm se valendo da manutenção de relações históricas de inclusão precarizada, produzida em articulação ao modelo capitalista de produção e consumo que temos gerado. Não percebemos questionamentos a respeito dos impactos dos padrões de intensificado consumo e descarte que geramos, em detrimento das condições de reposição energética do planeta, e tampouco vemos consideradas as contradições da manutenção de um discurso pro sustentatibilidade amparado na exploração de trabalhadores em ambientes de labuta extremamente insalubres e deteriorados.

A dinâmica produtiva estabelecida na cadeia produtiva da reciclagem parece corresponder às práticas usuais de mercado. Os catadores vivem a necessidade de ampliação da quantidade de resíduos para ampliarem os ganhos, cujo valor é controlado por uma rede de atravessadores mediante regulação de preços. Assim, condiciona-se ao aumento da produção laboral, e, consoante, da geração de resíduos nas cidades, a ampliação de rendimentos de uma população historicamente acostumada a acessar residualmente os recursos materiais e simbólicos gerados pelo sistema (apesar de sua real contribuição para manutenção deste). Sob estas condições, a sustentabilidade propalada negligencia 
as condições socioculturais de sua concretização e, neste ínterim, a ambiência relacional formadora em que a cadeia produtiva e, especialmente, a prática de catadores se efetivam cotidianamente.

Como provocação final, cabe citarmos uma das contribuições de Nilton Bueno Fischer. Ele afirma a necessidade de observarmos as práticas dos sujeitos desde sua interação com o espaço e o tempo onde se situam, que delimitará “o 'possível' de ser realizado por cada um” (Fischer, 2006, p. 60). O professor resgata as contribuições de Paulo Freire para caracterizar a 'identidade cultural' como construção indissociável do experienciado em vivências situadas em territórios de participação, e, neste ponto, emerge uma categoria que nos é inspiradora, a noção de entorno.

O entorno é empregado como condição concreta do sujeito, na sua individualidade, e bem como de suas relações com a materialidade de sua existência expressa por sua condição de quem vive, trabalha, sonha, vota, mora, estuda, etc. num determinado período histórico e numa determinada região (Fischer, 2006, p. 60).

Tal noção dispõe a tensão entre ação do sujeito e condicionantes dos espaços de convívio, chamando à compreensão dos atravessamentos entre sujeitos, práticas e o(s) lugar(es) onde estes se situam e constituem historicamente.

Recebido em 16 de dezembro de 2011 Aprovado em 04 de setembro de 2012

\section{Notas}

1 As informações que trazemos aqui decorrem da pesquisa realizada sob encomenda do Ministério da Educação, cuja demanda era caracterizar o perfil socioeducacional da população de catadores e/ou recicladores alocados em associações, cooperativas e grupos informais. Tal iniciativa atendia também uma demanda do Movimento Nacional de Catadores de Materiais Recicláveis (MNRC), que enunciava a precária inclusão deste segmento entre atividades educacionais regulares, almejando o desenvolvimento de políticas públicas na área.

2 Cabe esclarecer que abordaremos aqui as práticas desenvolvidas em espaços urbanos exclusivamente.

3 Quanto às denominações catador e reciclador, cabem dois esclarecimentos. Primeiramente, devemos assinalar que optamos por enunciar no masculino por mera formalidade linguística, embora exista uma predominância de mulheres nesta atividade, e também entre as pessoas consultadas. Além disso, destacamos a utilização destas duas nomenclaturas em reconhecimento às disputas identitárias que constituem este campo de trabalho, organizadas conforme a atuação de movimentos sociais e entidades representativas do segmento. $\mathrm{O}$ MNRC, por exemplo, prefere a primeira denominação, significando-a desde certa militância política. Não sendo foco deste texto, não detalharemos tais diferenciações e disputas.

Educação \& Realidade, Porto Alegre, v. 39, n. 2, p. 535-556, abr./jun. 2014.

Disponível em: <http://www.ufrgs.br/edu_realidade> 
Sujeitos, Políticas e Educação Ambiental na Gestão de Resíduos Sólidos

4 Os municípios foram os seguintes: Canoas, Cachoeirinha, Caxias do Sul, Dois Irmãos, Porto Alegre, Rio Grande e São Sepé, no Rio Grande do Sul; Blumenau e Florianópolis, em Santa Catarina; Curitiba e Londrina, no Paraná.

5 De acordo com Lopes (2006), é possível detectar em nosso país a existência de um processo "[...] de invenção, consolidação e avanço da temática ambiental, que se manifesta também por conflitos, por reações, recuperações e restaurações" (p. 32). Tratar-se-ia de um processo de gênese e consolidação de um campo simbólico nos últimos 25 anos, no qual se envolvem e relacionam diferentes sujeitos e grupos sociais, em atividades pertinentes à inquietação das forças ambientalistas com os paradoxos do desenvolvimento econômico.

6 Referimo-nos, aqui, à ação do MNCR, cuja presença percebemos em algumas das localidades pesquisadas, como Cachoeirinha/RS e Curitiba/PR.

7 Para mais detalhes, observar dados produzidos pelo Instituto Brasileiro de Geografia e Estatística (IBGE), no site <www.ibge.gov.br>.

8 Uma vez vinculado a uma associação, não há previsão legal de uso-fruto de direitos trabalhistas para o catador. Além disso, as visitas às associações eram acompanhadas da freqüente constatação de debilidade das instalações físicas e dos recursos necessários ao trabalho, desenvolvendo suas atividades em condições insuficientes e precárias. Encontramos, em alguns casos, unidades localizadas nas cercanias de córregos de água inclusive. Endossa tal constatação o dado (um tanto contraditório) de que a maioria destas prestadoras de um serviço público essencial não possuía licenciamento ambiental.

9 São exemplos, neste caso, as medidas emergenciais de realocação de famílias que catam em lixões, por exigência do Ministério Público.

10 As formações acadêmicas e trajetórias dos gestores públicos entrevistados diferem bastante, mas podemos considerar que, embora alguns tenham experiência ou titulação relacionadas à gestão ambiental ou reciclagem, a maioria se caracteriza pela atuação extensa na máquina estatal, tendo passado antes por secretarias ou departamentos distintos da área ambiental.

11 Referimo-nos, por exemplo, a orientações sobre segregação domiciliar de resíduos, manutenção da limpeza das ruas ou preservação da natureza. Sem desmerecer sua importância, como já expusemos antes, estas medidas não alteram o quadro socioambiental do trabalho de catadores, tampouco questionam a intensidade do consumo ou o volume de descartes produzidos numa dada realidade.

12 ELIAS, Norbert. O Processo Civilizador: uma história dos costumes. Rio de Janeiro: Jorge Zahar Ed., 1993.

13 Entendido aqui “[...] não como sinônimo de natureza intocada, mas como um campo de interações entre a cultura, a sociedade e a base física e biológica dos processos vitais, no qual todos os termos dessa relação se modificam dinâmica e mutuamente. Tal perspectiva considera o meio ambiente como espaço relacional [...]" (Carvalho, 2004, p. 37 - grifos nossos).

14 Neste caso, poderíamos citar como exemplo a pesquisa realizada na Associação Ecológica Rubem Berta, em Porto Alegre/RS, nos meses de março a maio/2010. Nesta iniciativa, convidamos catadoras a narrarem seus cotidianos por intermédio da produção de fotografias. Em três ensaios fotográficos, essas trabalhadoras expressaram em imagens (e relatos daí decorrentes) vivências e características que, muitas vezes, extrapolavam e/ou contrariavam os depoimentos marcados pela "ausência" e pela precariedade produzidas em entrevistas convencionais. Parte dos resultados deste trabalho foi publicada em artigo da Revista Latinoamericana de Tecnología Educativa. 


\section{Referências}

BOURDIEU, Pierre. Razões Práticas: sobre a teoria da ação. 11. ed. Campinas: Papirus, 2011.

BOURDIEU, Pierre. O Poder Simbólico. 11. ed. Rio de Janeiro: Bertrand Brasil, 2007.

CARVALHO, Isabel. A Invenção do Sujeito Ecológico: identidade e subjetividade na formação de educadores ambientais. In: SATO, Michelle; CARVALHO, Isabel (Org.). Educação Ambiental: pesquisa e desafios. Porto Alegre: Artmed, 2005. P. 51-63.

CARVALHO, Isabel. Educação Ambiental: a formação do sujeito ecológico. São Paulo: Cortez, 2004.

CARVALHO, Isabel. Os Sentidos de Ambiental: a Contribuição da Hermenêutica à Pedagogia da Complexidade. In: LEFF, Enrique. A Complexidade Ambiental. São Paulo: Cortez, 2003. P. 99-120.

CARVALHO, Isabel. A Invenção Ecológica: narrativas e trajetórias da educação ambiental no Brasil. Porto Alegre: Editora da UFRGS, 2001.

ELIAS, Norbert. O Processo Civilizador: uma história dos costumes. Rio de Janeiro: Jorge Zahar Ed., 1993.

GARCIA, Waldemar. Éticas Contemporâneas e Meio Ambiente. In: GUIMARÃES, Leandro et al. (Org.). Tecendo Subjetividades em Educação e Meio Ambiente. Florianópolis: NUP/CED/UFSC (Coleção Cadernos CED; 6), 2003. P. 41-48.

FISCHER, Nilton Bueno. Educação e Desenvolvimento numa Perspectiva Relacional entre Tempos - Internos e Externos - das Ações Cotidianas dos Sujeitos. In: PENNA, Ricardo (Org.). Conhecimento, Sustentabilidade e Desenvolvimento Regional. Canoas: UNILASALLE, 2006. P. 59-73.

FUNDAÇÃO INSTITUTO BRASILEIRO DE GEOGRAFIA E ESTATÍSTICA (IBGE). Síntese dos Indicadores Sociais: uma análise das condições de vida da população brasileira - 2009. Estudos e Pesquisas, Informações Demográficas e Socioeconômicas, n. 26. IBGE: Rio de Janeiro, 2009.

FUNDAÇÃO INSTITUTO BRASILEIRO DE GEOGRAFIA E ESTATÍSTICA (IBGE). Pesquisa Nacional de Saneamento Básico (PNSB). IBGE: Rio de Janeiro, 2002.

LAGEMANN, Eugênio. A Formação Socioeconômica da Região Sul do Brasil. Textos para Discussão - UFRGS, n. 05, 1998.

LOPES, José. Sobre os Processos de Ambientalização dos Conflitos e sobre Dilemas de Participação. Horizontes Antropológicos, Porto Alegre, ano 12, n. 25, p. 31-64, jan./jun. 2006.

LISBOA, Cassiano Pamplona et al. Estudo do Perfil Sócio-Educacional da População de Catadores de Materiais Recicláveis Organizados em Cooperativas, Associações e Grupos de Trabalho. Porto Alegre: UFRGS/SECAD/MEC, 2010.

LISBOA, Cassiano Pamplona et al. Itinerários de Pesquisa: educação ambiental e o trabalho com grupos de rememoração. In: SEMINÁRIO DE PESQUISA QUALITATIVA - FAZENDO METODOLOGIA, 8. Anais... Pelotas: UFPEL, 2009.

MARTINS, Clítia. Catadoras/Recicladoras na Região Metropolitana de Porto Alegre: organização do trabalho e identidade profissional. Mulher e Trabalho, Porto Alegre, v. 5, p. 65-78, 2003.

MARTINS, José de Souza. Sociedade Vista do Abismo. Rio de Janeiro: Vozes, 2002.

Educação \& Realidade, Porto Alegre, v. 39, n. 2, p. 535-556, abr./jun. 2014. 
Sujeitos, Políticas e Educação Ambiental na Gestão de Resíduos Sólidos

MEYER, Dagmar; FISCHER, Nilton B.; STEPHANOU, Maria. Estudo do Perfil Sócio-Educacional da População de Catadores de Materiais Recicláveis Organizados em Cooperativas, Associações e Grupos de Trabalho - Relatório Final. Brasília: SECAD/MEC - UFRGS, 2010.

MONTALI, Lilia. Família e Trabalho na Reestruturação Produtiva. Revista Brasileira de Ciências Sociais, São Paulo, v. 15, n. 42, p. 55-71, fev. 2000.

OLIVEIRA, Wilson. A Utilização do Referencial Ambientalista como Justificativa à Implantação do Sistema de Coleta Seletiva de Lixo em Porto Alegre. Porto Alegre: UFRGS, 1995.

Leandro Rogério Pinheiro é doutor em Educação. Professor da Faculdade de Educação da Universidade Federal do Rio Grande do Sul (UFRGS) em Porto Alegre, no estado do Rio Grande do Sul.

E-mail: leandropinheiro75@gmail.com

Márcio de Freitas do Amaral é doutorando no Programa de Pós-Graduação em Educação da Universidade Federal do Rio Grande do Sul (UFRGS) em Porto Alegre, no estado do Rio Grande do Sul.

E-mail:mfamaral@gmail.com

Cassiano Pamplona Lisboa é doutor em Educação (PPGEdu/UFRGS). Professor do Instituto Federal de Educação, Ciência e Tecnologia do Rio Grande do Sul (IFRS) em Porto Alegre, no estado do Rio Grande do Sul.

E-mail: cassiano.lisboa@gmail.com

Tiago de Mello Cargnin é doutorando em Educação no Programa de Pós-Graduação da Pontifícia Universidade Católica do Rio Grande do Sul (PUCRS). Professor do Centro Universitário UNILASALLE em Canoas, no estado do Rio Grande do Sul.

E-mail: tiago_cargnin@yahoo.com 